\title{
APLICAÇÃO DE INULINA E SUCRALOSE EM IOGURTE
}

\section{APLICATION OF INULIN AND SUCRALOSE IN YOGURT}

\author{
Eliana Queiroz Bortolozo ${ }^{1}$; Maria Helena Rosinek Quadros ${ }^{2}$ \\ ${ }^{1}$ Universidade Tecnológica Federal do Paraná - UTFPR - Ponta Grossa - Brasil - bortolozopg@uol.com.br \\ ${ }^{2}$ Frigol Comercial - Setor de Controle de Qualidade - São Paulo - Brasil - mariquadros@hotmail.com
}

\begin{abstract}
Resumo
Este estudo teve por objetivo desenvolver um iogurte adicionado de inulina, caracterizando-se prebiótico e para fins especiais, como alternativa para uma alimentação mais saudável e que possa ser consumido por pessoas com dieta restrita em gordura ou açúcares. A partir desta proposta, foi elaborado um iogurte adicionado de inulina e sucralose, com matéria-prima desengordurada. Para tanto, foram realizados cinco ensaios, incluindo concentrações diferentes de sucralose. O melhor resultado foi obtido no ensaio cuja concentração de inulina era de 5\%, e de sucralose 0,05\%, o qual apresentou boa consistência e um pH de 4,53. No produto elaborado, os resultados microbiológicos revelaram: $<10$ de coliformes fecais; $4 \times 10$ de coliformes totais; ausência de Salmonella. Os resultados físico-químicos determinaram: 0,50\% de gordura; $5,3 \%$ de proteína total; $1,52 \%$ de resíduo mineral fixo; $8,86 \%$ de açúcares totais; $0,95 \%$ de acidez em ácido lático e $1294.74 \mathrm{~mm}^{2} / \mathrm{s}^{1}$ de viscosidade. A análise sensorial, feita através da escala hedônica, resultou numa média de 8,2 no teste de aceitação. Com base nos resultados obtidos, pode-se concluir que os objetivos propostos foram atingidos, obtendo-se um produto de boa aceitação, baixa concentração calórica, isento de gorduras e rico em fibras solúveis, podendo ser classificado como um produto para fins especiais e produto funcional.
\end{abstract}

Palavras-chave: iogurte; inulina; alimento funcional.

\section{Introdução}

Os alimentos funcionais constituem hoje a prioridade de pesquisa na área de nutrição e tecnologia de alimentos, levando-se em conta o interesse do consumidor em alimentos mais saudáveis, que além de nutrir possam modelar o sistema fisiológico do organismo (FERREIRA, 2000; NITSCHKE e UMBELINO, 2002; KIMURA, 2002; OLIVEIRA, 2002).

O setor lácteo não foge a esta tendência de produzir alimentos em que a funcionalidade é o atributo principal. Com uma grande variedade de produtos no mercado brasileiro, entidades desenvolvem pesquisas para a formulação de produtos que potencializem ainda mais os benefícios do leite e seus derivados (MATSUBARA, 2001; BELCHIOR, 2003). 
Várias denominações têm sido empregadas para identificar alimentos funcionais, como: pharma, designer, food, funcional food, active food, nutraceuticals, health food, medical food, sendo que esta última tem sido evitada, visto estar regulamentada pela Agência de Remédios e Alimentos dos Estados Unidos (FDA) (PUPIN, 2001).

Pesquisas mostram que os consumidores estão cada vez mais preocupados em obter informações sobre alimentos funcionais e estão tentando mudar seus hábitos alimentares, com vistas a melhorar a saúde. O mercado para produtos com apelo saudável ou com diferenciado conteúdo de nutrientes (baixa caloria, enriquecidos com fibras, etc.) continua a crescer. Os oligossacarídeos, por exemplo, permitem ao fabricante a oportunidade de satisfazer essas duas demandas ao mesmo tempo, pois além de suas propriedades funcionais e nutricionais, oferecem também benefícios tecnológicos como substituto do açúcar (USHIJIMA, 2001).

O avanço do conhecimento mostrando a relação entre a dieta e saúde/doença, além dos custos da saúde pública e interesses econômicos da indústria, têm gerado novos produtos cujas funções pretendem ir além do conhecido papel nutricional e sensorial dos alimentos (LAJOLO, 2001).

Segundo SGARBIERI e PACHECO (1999), alimento funcional é qualquer alimento, natural ou preparado, que contenha uma ou mais substâncias, classificadas como nutrientes ou não nutrientes, capazes de atuar no metabolismo e na fisiologia humana, promovendo efeitos benéficos para a saúde, podendo retardar o estabelecimento de doenças crônico-degenerativas e melhorar a qualidade e a expectativa de vida das pessoas. O alimento funcional pode ainda ser definido como: qualquer alimento ou ingrediente alimentar, que pode proporcionar benefícios à saúde, além daqueles conferidos pelos nutrientes presentes no alimento. Portanto, os alimentos funcionais são alimentos, e não medicamentos (CANDIDO e CAMPOS, 1996; OLIVEIRA, 2002; SOUZA, MAIA e NETO, 2003).

Os principais grupos biologicamente ativos atualmente conhecidos como ingredientes funcionais são as fibras solúveis e insolúveis, flavonóides, carotenóides, fitoesteróis, fitoestanóis, ácidos graxos (ômega 3 e ômega 6), prebióticos e probióticos (BELLO, 1995; TORRES, 2001).

O grupo das fibras solúveis (maçã, pera, aveia, feijão, ervilha, lentilha) e as insolúveis (vegetais, trigo, centeio) são dos primeiros nutrientes funcionais utilizados na agregação do valor em alimentos industrializados. As fibras solúveis, por exemplo, ligam-se aos sais biliares no intestino, diminuindo sua reabsorção, o que resulta em menos colesterol disponível no fígado para a síntese de lipoproteínas (SOARES, 2000; COSTA, 2001).

$\mathrm{Na}$ busca de novos alimentos funcionais, os prebióticos têm sido estudados como ingredientes em vários alimentos, entre eles bebidas lácteas funcionais ou simbióticas. Prebiótico, geralmente um oligossacarídeo, é o ingrediente de um alimento que não é transformado no processo 
digestivo e que afeta beneficamente o homem através da estimulação seletiva no desenvolvimento e/ou atividade de um número limitado de microrganismos probióticos no cólon (SILVA, 2000).

Geralmente, os prebióticos se constituem de oligossacarídeos, carboidratos de alto peso molecular, encontrados na natureza, como a rafinose, ou obtidos através de reações enzimáticas, como o galacto-oligossacarídeo, o frutooligossacarídeo (FOS) e o isomalto-oligossacarídeo (KIMURA, 2002). São substâncias direcionadas para alterar alguns gêneros da microbiota intestinal e não sofrem as dificuldades de sobrevivência que os microrganismos probióticos precisam enfrentar. Algumas características são importantes, ao se selecionar prebióticos: essas substâncias não devem ser hidrolizadas ou absorvidas na parte superior do trato intestinal, precisam ser substratos seletivos para um número limitado de microrganismos habitantes do cólon e devem alterar essa microbiota tornando-a mais saudável para o hospedeiro. Certos carboidratos, oligo e polissacarídeos, ocorrem naturalmente e podem ser usados como prebióticos (ROBERFROID, 1998).

A funcionalidade dos alimentos prebióticos está relacionada a uma atuação direta com: aumento do tempo de esvaziamento do estômago; modulação do trânsito do trato gastrointestinal (GOT); diminuição de colesterol via adsorção de ácidos biliares e por meio de atuação indireta, modulando a fermentação microbiana pelo estímulo de bactérias bífidas responsáveis por aumento de SCFA (ácidos graxos de cadeia curta), diminuição de $\mathrm{pH}$ e diminuição na absorção da amônia (FERREIRA, 2000).

A inulina é uma fibra solúvel, considerada um ingrediente prebiótico. Comumente extraída da raiz da chicória, oferece uma gama de benefícios nutricionais e tecnológicos. Pode trazer benefícios para o sistema digestivo, pois a ingestão de ingredientes prebióticos melhora o equilíbrio da nossa microflora intestinal, aumentando significativamente a quantidade de bifidobactérias benéficas, inibindo os patógenos. O resultado disso é que o sistema digestivo trabalha melhor, aumentando a absorção dos nutrientes dos alimentos ingeridos. Pode ser utilizada como substituto da gordura, porque estabiliza a água em uma estrutura cremosa, mantendo a mesma percepção de paladar de gordura. Também melhora a textura e a o sabor (NEVEN, 2001; MULLER, 2001; NITSCHKE e UMBELINO, 2002; MONTAN, 2003).

A inulina e a oligofrutose extraídas da chicória são classificadas legalmente como ingredientes alimentícios (e não como aditivos) em todos os países da União Européia, bem como na Suíça e na Noruega. As autoridades na Austrália, Canadá, Israel, Japão e Nova Zelândia chegaram à mesma conclusão. Nos Estados Unidos, foi confirmado o estatus GRÃS (Generally Recognized As Safe) para inulina e oligofrutose (NEVEN, 2001).

As diferenças no tamanho das cadeias da inulina e das oligofrutoses são também responsáveis pelas diferenças entre suas propriedades. Devido às cadeias mais longas, a inulina é 
menos solúvel que as oligofrutoses e possui capacidade de formar microcristais quando misturada com água e leite. Estes microcristais interagem para formar uma mistura cremosa e macia, promovendo a sensação de presença de gordura. A inulina tem sido utilizada com sucesso como substituto da gordura, em recheios prontos, sobremesas congeladas e molhos (NEVEN, 2001; NITSCHKE e UMBELINO, 2002; BONDT, 2003; MONTAN, 2003).

O objetivo deste estudo foi desenvolver um iogurte com propriedades funcionais prebióticas e para fins especiais, levando-se em conta que o iogurte é um alimento de fácil aceitação, rico em nutrientes, podendo contribuir com o mercado de consumidores que procuram produtos capazes de manter a saúde e retardar o aparecimento de doenças metabólicas.

\section{Material e métodos}

O produto foi desenvolvido nos laboratórios da Universidade Tecnológica Federal do Paraná, Campus Ponta Grossa e da Sadia SA. Como matéria-prima utilizou-se leite desnatado; leite em pó desnatado; inulina em pó; sucralose; cultura láctica “Latobacillu bulgaricus e Streptococcus thermophilus" (1:1) (FIGUEIREDO e PORTO, 2002).

Sucralose é derivado do açúcar através de um processo patenteado de multi-passos, que substitui seletivamente 3 átomos de cloro por 3 grupos de hidrogênio-oxigênio na molécula do açúcar. Essa oportuna troca de átomos de cloro cria uma estrutura molecular que é excepcionalmente estável e aproximadamente 600 vezes mais doce que o açúcar (CAMPOS, 2002). A sucralose apresenta o perfil de sabor mais semelhante ao do açúcar, em relação a todos os outros edulcorantes, porém sem o indesejável aftertast amargo/metálico. Suas ligações carbono-cloro são estáveis e não hidrolisadas durante a digestão, sendo rapidamente excretadas nas fezes. Avaliada por quinze anos, foram realizados por volta de cento e quarenta estudos em animais e humanos, concluindo que não apresenta efeitos teratogênicos, toxicidade ou carcinogenicidade (CAMPOS, 2002; SALGADO, 2004; VIGGIANO, 2004).

A metodologia utilizada neste estudo, para o desenvolvimento do iogurte, baseou-se naquela descrita por TAMINE e ROBINSON (1991), sendo realizados cinco ensaios, com as seguintes formulações:

- Ensaio 1: leite desnatado; leite desnatado em pó (3\%); açúcar (8\%); fermento (0,5\%).

- Ensaio 2: leite desnatado; leite desnatado em pó (3\%); inulina (5\%); fermento (0,5\%).

- Ensaio 3: leite desnatado; leite desnatado em pó (3\%); inulina (5\%); fermento $(0,5 \%)$; sucralose $(0,1 \%)$.

- Ensaio 4: leite desnatado; leite desnatado em pó (3\%); inulina (5\%); fermento (0,5\%); sucralose $(0,07 \%)$. 
- $\quad$ Ensaio 5: leite desnatado; leite desnatado em pó (3\%); inulina (5\%); fermento $(0,5 \%)$; sucralose $(0,05 \%)$.

O iogurte elaborado no ensaio 1 foi utilizado para comparar a viscosidade do iogurte elaborado no ensaio 5, a fim de avaliar um possível aumento da viscosidade com a adição de inulina. Todas as análises de caracterização do produto foram realizadas com amostra do iogurte obtido no ensaio 5, considerado o de resultado mais satisfatório.

As análises físico-químicas seguiram as Normas Analíticas do Instituto Adolfo Lutz (1985). Foram realizadas as seguintes análises:

- $\quad$ análises de acidez em ${ }^{\circ}$ Dornic;

- análises de açúcares totais, pelo método de Fehling;

- determinação de gordura, pelo método de Soxhler;

- determinação de proteína, pelo método de Kdjehal;

- determinação de resíduo mineral fixo;

- $\quad \mathrm{pH}$, determinação direta por phmetro;

- viscosidade, através da medida do tempo em segundos.

Todas as análises foram realizadas em triplicata. Para determinação da viscosidade, foram utilizadas amostras da formulação padrão (ensaio 1) e da formulação elaborada com inulina (ensaio $5)$.

Para análise de Coliformes totais e fecais, foram utilizados os métodos rápidos de análise, através do Petrifilm da 3M. Já para a análise de Salmonella sp., utilizou-se a metodologia de SILVA et al. (1997).

O produto obtido no ensaio 5 foi submetido à análise sensorial, com um teste de escala hedônica de nove pontos (DUCTOSKI,1996). Este é um dos métodos mais utilizados em testes sensoriais afetivos, sendo possível calcular a média e a magnitude da diferença de aceitação entre os produtos, e também verificar possíveis segmentações de opiniões dos consumidores (MORAES, 1985; GARRUTI, 1985; MEILGAARD, 1996; SGS, 2003).

A análise sensorial abrangeu uma população de 31 provadores não treinados. Os testes foram aplicados no laboratório de Análise Sensorial da Universidade Tecnológica Federal do Paraná, Campus Ponta Grossa. Os provadores receberam a amostra codificada por número aleatório e água mineral para realizarem o branco. Foram orientados para não trocarem opiniões na hora dos testes e realizá-los com o máximo de atenção. Os resultados foram avaliados através da média final. 


\section{Resultados e discussão}

No primeiro ensaio, para elaboração de um iogurte tradicional, depois de 4 horas a uma temperatura de $42{ }^{\circ} \mathrm{C}$, este apresentou baixa consistência (AQUARONE, et al., 1983; BEHMER, 1984), com pH igual a 4,95. Após 6 horas, o iogurte apresentou uma consistência desejável (AQUARONE, et al., 1983; BEHMER, 1984), com um pH igual a 4,47.

O segundo ensaio apresentou um iogurte com uma concentração de 5\% de inulina, sem adição de sucralose. Após 4 horas, o produto apresentou uma consistência desejável, porém com um pH igual a 4,85. Foi colocado na estufa por um tempo adicional de 2 horas, para torná-lo mais ácido, atingindo então um pH igual a 4,53.

No terceiro ensaio, adicionou-se $0,10 \%$, em peso, de sucralose, e $5 \%$ de inulina. Depois de 4 horas na estufa, foi constatada uma consistência desejável, porém com um pH de 4,8. Levado o produto à estufa por mais 2 horas, apresentou um $\mathrm{pH}$ igual a 4,53. Mas como foi observado sabor muito adocicado, optou-se por reduzir, a concentração de sucralose.

No quarto ensaio foi feita a adição de $5 \%$ de inulina e $0,07 \%$ de sucralose, chegando-se a uma consistência desejável e $\mathrm{pH}$ igual a 4,95. Depois de mais 2 horas na estufa, apresentou um $\mathrm{pH}$ de 4,56. O sabor do iogurte ainda se manteve muito doce.

No quinto ensaio foi adicionado $5 \%$ de inulina e $0,05 \%$ de sucralose, alcançando-se uma boa consistência e um $\mathrm{pH}$ de 5,01. Após permanecer por mais 2 horas na estufa, apresentou pH igual a 4,53. O sabor adocicado tornou-se mais agradável, semelhante ao do açúcar, conforme citado na literatura (ORAFTI, 2000; CAMPOS, 2002).

A sucralose foi adicionada juntamente com os outros ingredientes, uma vez que apresenta resistência térmica e boa dissolução, sendo um produto de fácil utilização (ORAFTI, 2000).

A baixa concentração de sucralose utilizada no ensaio 5 , de $0,05 \%$, representando cerca de 1200 vezes o poder do açúcar, ficou acima das 600 vezes citadas na literatura (CAMPOS, 2002; CAMPOS, 2002). Este resultado vem ao encontro de outros estudos que demonstraram um aumento da ação edulcorante da sucralose, através de um sinergismo com a inulina (NEVEN 2001; BONDT, 2003).

Quanto aos resultados referentes ao $\mathrm{pH}$, fator diretamente relacionado à viabilidade dos microrganismos e da acidez, chegou-se ao $\mathrm{pH}$ final igual a 4,53. Resultado considerado adequado, tendo-se em vista que recomendada-se que o pH para iogurtes esteja entre 4,5 à 4.6 (AQUARONE, et al., 1983). Segundo KURMANN (1977),o pH ideal para leites fermentados é próximo a 4,5, porquanto valores inferiores podem levar à rejeição por parte dos consumidores e favorecer a contração do coágulo, devido à redução da hidratação das proteínas, causando dessoramento. 
Valores de $\mathrm{pH}$ acima de 4,6 favorecem a separação do soro, porque o gel não foi suficientemente formado (BRANDÃO, 1995).

A acidez observada chegou a $94^{\circ} \mathrm{D}$, atendendo ao estabelecido pela legislação brasileira em vigor, que é de 0,60 a $150^{\circ} \mathrm{D}$ (BRASIL, 1997).

O teor de gordura verificado foi de $0,50 \%$, sendo classificado o iogurte em estudo como produto restrito em gordura, de acordo com a Portaria 29 (BRASIL,1998). E, conforme a Resolução GMC 47/97, foi classificado como iogurte desnatado (BRASIL, 1997).

O teor de proteína apresentou-se em 5,3\%, atendendo ao estabelecido pela legislação brasileira em vigor, que é de no mínimo 2,9\% (BRASIL,1997). O teor de resíduo mineral fixo obtido nas análises foi de $1,52 \%$, e o de açúcares totais foi de $8,86 \%$. A Tabela 1 apresenta a composição centesimal do produto elaborado.

Com a adição de inulina, o produto foi enriquecido com fibra, diferindo, portanto, do iogurte tradicional, que é isento deste ingrediente, podendo-se utilizar o claim de fibras (MITCHEL, 2002). A baixa concentração de gordura permite a alegação de um produto para fins especiais, especificamente com restrição de gordura e açúcares (BRASIL). Estas características, ou seja: produto rico em fibras solúveis, com baixa taxa de gordura e sem sacarose, possibilitam a indicação deste iogurte para consumidores diabéticos, obesos e com índices lipídicos séricos elevados (OLIVEIRA, 1998; MAHAN, 1998).

Tabela 1 - Composição centesimal do iogurte com inulina.

\begin{tabular}{cc}
\multicolumn{2}{c}{$\begin{array}{c}\text { Informação Nutricional } \\
(\text { Quantidade de 100g) }\end{array}$} \\
\hline Calorias (kcal)* \\
Proteínas (g) \\
Gorduras $(\mathrm{g})$ \\
Carboidratos $(\mathrm{g})$ \\
Fibras (g)
\end{tabular}

A Tabela 2 apresenta os resultados da viscosidade do iogurte tradicional e do iogurte elaborado neste estudo. É possível observar uma elevação da viscosidade com a adição de inulina, que se deve provavelmente à sua ação de interagir com a água, formando microcristais, tornando a mistura mais cremosa e macia (NITSCHKE e UMBELINO, 2002; BONDT, 2003; MONTAN, 2003). 
Tabela 2 - Resultados da viscosidade do iogurte com inulina.

\begin{tabular}{cc}
\hline Iogurte & Resultados obtidos \\
\hline Iogurte com inulina & $1294.74 \mathrm{~mm}^{2} / \mathrm{s}^{1}$ \\
Iogurte tradicional & $899.45 \mathrm{~mm}^{2} / \mathrm{s}^{1}$ \\
\hline
\end{tabular}

Conforme apresentado na Tabela 3, os resultados de coliformes fecais, totais e Salmonella $s p$., encontrados situam-se dentro dos limites propostos pela legislação brasileira vigente (BRASIL 2001). Tais resultados são satisfatórios, posto que atendem aos requisitos mínimos de qualidade para o consumo humano.

Tabela 3 - Resultados microbiológicos do iogurte com inulina.

\begin{tabular}{ccc}
\hline Microrganismo pesquisado & Resultado & Padrão \\
\hline Coliformes Fecais & $<10$ & 10 \\
Coliformes Totais & $4 \times 10 \mathrm{UFC} / \mathrm{g}$ & $10^{2}$ \\
Salmonella & Ausente & Ausente \\
\hline
\end{tabular}

$\mathrm{Na}$ avaliação sensorial, utilizou-se uma escala de 1 (desgostei muitíssimo) até 9 (gostei muitíssimo). A resposta dos consumidores variou de 7 (gostei moderadamente) a 9 (gostei muitíssimo), conforme demonstra a Tabela 4. Sendo que sete consumidores atribuíram nota 7 (gostei moderadamente), onze consumidores deram nota 8 (gostei muito) e treze consumidores colocaram nota 9 (gostei muitíssimo), obtendo-se uma média final de 8,2.

O que foi observado pelos provadores que estão acostumados a consumir um iogurte natural geralmente sem açúcar, foi o teor de doçura e a consistência, o que pode representar um ponto positivo para o bom desempenho nas vendas deste produto, de vez que a média ficou entre 8 (gostei muito) e 9 (gostei muitíssimo).

\section{Conclusão}

O estudo resultou na elaboração de um iogurte semelhante ao tradicional, de boa aceitação, com baixa concentração calórica, isento em gorduras e rico em fibras solúveis, com resultado adequado, do ponto de vista microbiológico, o que justifica sua classificação como um produto para fins especiais e produto funcional. 
O uso da sucralose, como substituto do açúcar, apresentou fácil utilização, baixa concentração e possível sinergismo com a inulina.

O uso da inulina, como agregação de valores funcionais ao iogurte, apresentou fácil utilização, proporcionando aumento da viscosidade no produto, amenizando a baixa concentração de gordura.

Este produto pode ser uma alternativa no mercado de fermentados, visto como - além de poder gerar vários benefícios para a saúde - pode ser destinado a consumidores diabéticos ou obesos. Novos estudos poderiam ser realizados, a fim de serem adicionadas bactérias lácticas probióticas, para caracterizar o produto como um alimento simbiótico, que representa outra tendência do mercado.

\begin{abstract}
This work aimed to elaborate an inulin added yogurt, with prebiotic features and for special purposes, as an alternative for a healthier food and that can be used by people with a fat or sugarrestricted diet. From this proposal, was elaborated a inulin and sucralose added yogurt, with defatted raw material. For this, five essays were undertaken, including different concentrations of sucralose. The best result was obtained in the essay with $5 \%$ of inuline concentration, and $0,05 \%$ of sucralose concentration, which showed good consistency and $\mathrm{pH} 4,53$. For the elaborated product, microbiological results revealed: $<10$ of fecal coliform; 4 x 10 of total coliform; absence of Salmonella. Physical-chemical results were: $0,50 \%$ of fat; $5,3 \%$ of total protein; $1,52 \%$ of ash; $8,86 \%$ of total sugar; $0,95 \%$ of acidity in lactic acid and $1294.74 \mathrm{~mm}^{2} / \mathrm{s}$ of viscosity. Sensoryl analysis, undertaken through hedonic scale, showed a medium of 8,2 in the acceptation test. Based on the obtained results, it was brought to a conclusion that objectives were reached, as it was obtained a product with good acceptation, low caloric concentration, no fat and rich in soluble fiber; it can be classified as a product with specific purpose and a functional product.
\end{abstract}

Key-words: yogurt; inulin; functional foods.

\title{
5. Referências
}

AQUARONE, E.; LIMA, U.A.; BORZANI, W. Biotecnologia: alimentos e Bebidas produzidos por fermentação. São Paulo: Edgar Blugher Ltda., 1983.

BELCHIOR, F. Lácteos 100\% saudáveis. Leite e derivados, n.69, v.12., p.30-33, 2003.

BELLO, J. Os Alimentos Funcionais e Nutracêuticos: Nova gama de produtos na indústria alimentícia, São Paulo, 1995.

BHEMER, M.L.A. Tecnologia do leite: revisada e atualizada. São Paulo: Nobel, 1984.

BONDT, V. Novas Tendências para Bebidas Funcionais. Revista Brasil Alimentos, n.18, 2003.

BRANDAO, S.C.C. Tecnologia da produção de iogurte. Revista Leite e Derivados, n.25, v.5., p.24-38, 1985.

BRASIL. Ministério da Agricultura e Abastecimento. Regulamento Técnico de Identidade e Qualidade de Leites Fermentados. Brasília, DIPOA, 1997. 
BRASIL. Ministério da Saúde. Secretária de Vigilância Sanitária. Portaria no 29 de 13 de Janeiro de 1998. In: LEGISLAÇÃO COMENTADA. De produtos lácteos e de alimentos para fins especiais-diet, light e enriquecidos, padrões de identidade e qualidade. São Paulo: Fonte Comunicações, 1998.

BRASIL. Ministério da Saúde. Secretária de Vigilância Sanitária. Portaria no 29 de 13 de Janeiro de 1998. Regulamento de alimentos para fins especiais; disponível em: < $\underline{\text { http://www.anvisa.gov.br/legis/portarias/29 98.htm }>}$ acesso em : 26/04/2005.

BRASIL. Ministério da Saúde. Secretária de Vigilância Sanitária. Resolução - RDC nº 12, de 2 de janeiro de 2001. Regulamento técnico sobre padrões microbiológicos para alimentos, disponível em: < http://www.anvisa.gov.br/legis/resol/12_01rdc.htm> acesso em : 26/04/2005.

CAMPOS, M. B. Sucralose: A Revolução em Adoçantes, Revista Food Ingredients, n. 19, v. 4., 2002.

CANDIDO, L. M. B.; CAMPOS, A. M. Alimentos para Fins Especiais: Dietéticos, São Paulo: Varela, 1996.

COSTA, R. P. Fibras: inter-relação com a doença cardiovascular. Qualidade em Alimentação Nutrição, n.8, 2001.

DUCTOSKY, S. D. Análise Sensorial de Alimentos. Curitiba: Editora Champagnat, 1996.

FERREIRA, C.L.L.F.Tecnologia para Produtos Lácteos Funcionais: Probióticos, Bol. SBCTA, n. 36, v.1., 2000.

FIGUEIREDO, M.G.; PORTO, E. Qualidade da matéria-prima no processamento industrial do iogurte natural. Revista Indústria de Laticínios, n.18, 2002.

CAMPOS, M.B. Aplicação de Sucralose em Iogurtes e Preparados de Frutas para Iogurtes. Food Ingredients, n. 19, 2002.

GARRUTI, R.S. Métodos sensoriais em controle de qualidade na indústria de alimentos. Campinas: Fundação de pesquisa e tecnologia André Tosello, 1985.

KIMURA, Y.O. Alimentos Simbióticos: A combinação de microrganismos probióticos com ingredientes prebióticos representa uma nova oportunidade no desenvolvimento de produtos lácteos saudáveis. Revista Laticínios, n.22, 2002.

KURMANN, J. A. Os fatores biológicos e técnicos da fabricação do iogurte. In: CONGRESSO DE LATICÍNIOS, 4., Juiz de Fora. Anais..., 1977.

LAJOLO, F.M. Alimentos funcionais: uma visão geral. In: ANGELIS, R.C. Importância de alimentos vegetais na proteção da saúde, São Paulo: Editora Atheneu, 2001.

MAHAN, L. K. Krause: Alimentos, Nutrição e dietoterapia, 9 ed., São Paulo: Roca,1998.

MATSUBARA, S. Alimentos Funcionais: Uma tendência que abre perspectivas aos latícinios, Revista Latícínios, n. 34, v. 6., 2001.

MEILGAARD, M., CIVILlE, G.V., CARR, B.T. Sensory evaluationtechniques. v. I, Florida - USA: CRC Press, 1987.

MITCHEL, H. L. Bebidas Enriquecidas com Fibras, Revista Food Ingredients, n. 20, v.10. 2002.

MÚLLER, V., Alimentos Funcionais, Revista Laticínios, n 34, v.6., 2001.

MONTAN, M., As fibras invisíveis, Revista Brasil Alimentos, n 19, v.4., 2003.

MORAES, M.A.C. Métodos para avaliação sensorial de alimentos. 5 ed. Campinas: UNICAMP, 1985.

NEVEN, E. Inulina e oligofrutose - ingredientes multifuncionais para o desenvolvimento de produtos lácteos, Revista Leite e Derivados, n. 6, v. 11., 2001.

NITSCHKE, M.; UMBELINO,D.C. Frutoooligossacarídeos: Novos Alimentos Funcionais, Bol. SBCTA, n. 36, v. 1., 2002 . 
NORMAS ANALÍTICAS DO INSTITUTO ADOLF LUTZ, Métodos Químicos e Físicos para Análise de Alimentos, 3 ed., São Paulo, 1985.

OLIVEIRA, A.F.A. Leites Fermentados e Bebidas Lácteas, Ital: Campinas, 1997.

OLIVEIRA, S.P. Alimentos Funcionais: Aspectos Relacionados ao Consumo, Revista Food Ingredients, n.20, 2002.

ORAFTI, A.F.I. Inovar com Raftilose, São Paulo, 2003.

PUPIN, A.M. O Agronegócio do Leite e os Alimentos Lácteos Funcionais. Juiz de Fora, 2001.

ROBERFROID, MARCEL Alimentos funcionais: o caso dos pró e prebióticos . In: Seminário da Nestlé Nutrition, 1998, China, Anais ... Vevey, Suiça, Nestlé Nutrition Services, 1998.

SGARBIERI, V.C.; PACHECO, M.T.B. Revisão: alimentos funcionais fisiológicos. Braz. J. Food Technnol., n.1, v.2., 1999.

SGS DO BRASIL LTDA, Conceitos e Técnicas de Avaliação Sensorial, Manual de Treinamento, n. $2 ., 2003$.

SILVA, N.; JUNQUEIRA, V.C.A.; SILVEIRA, N.F.A. Manual de Métodos de Análise Microbiológica de Alimentos, São Paulo: Livraria Varela, 1997.

SILVA, L.L. STAMFORD, T.L.M., Higiene Alimentar. n.68, v.14., 2000.

SOARES; VIEIRA; FRANCISCO; SÁ; Fibras Alimentares: Histórico, classificação e efeitos fisiológicos. In: Simpósio Sul-Brasileiro de Alimentação e Nutrição: História e Arte, 2000, Anais...Florianópolis: Departamento de Nutrição, 2000.

SOUZA, P. H. M. ; NETO, M. A. S.; MAIA, G. A. Componentes Funcionais nos Alimentos, Boletim SBCTA, n.37, v.2., 2003.

TAMIME, A. Y; ROBINSON, R. K. Yogur, ciencia y tecnologia. Zaragoza. España: Acribia, 1991.

TORRES, E. A. F. S. Alimentos em questão: uma abordagem técnica para as dúvidas mais comuns, São Paulo: Ponto Crítico, 2001.

USHIJIMA, H. H. Oligossacarídeos e suas Propriedades Funcionais, Revista Latícinios, n.34, v.6., 2001.

VIGGiAnO, C. E. O Produto Dietético no Brasil e sua Importância para Indivíduos Diabéticos, disponível em <http://www.bdbomdia.com/ed_68/terapeutica/dmnut/artigo_09.html $>$, acesso em 8/06/2005.

\section{Dados completo do primeiro autor:}

Eliana Queiroz Bortolozo

Universidade Tecnológica Federal do Paraná

Curso de Tecnologia em Alimentos

Professora

Rua Euzébio da Mota, 361. Ponta Grossa, Paraná, Brasil. Cep:84551530

42- 32204823

email:bortolozopg@uol.com.br 